\title{
Attacking and defensive styles of play in soccer: analysis of Spanish and English elite teams
}

\author{
Javier Fernandez-Navarro (i) ${ }^{\mathrm{a}, \mathrm{b}}$, Luis Fradua ${ }^{\mathrm{b}}$, Asier Zubillagac, Paul R. Ford ${ }^{\mathrm{a}}$ and Allistair P. McRobert ${ }^{\mathrm{a}}$
}

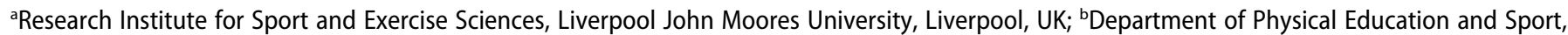
Faculty of Sport Sciences, University of Granada, Granada, Spain; 'Department of Physical Education and Sport, Faculty of Sport Sciences, UPV/EHU University of the Basque Country, Vitoria-Gasteiz, Spain

\section{ABSTRACT}

The aim of this study was to define and categorise different styles of play in elite soccer and associated performance indicators by using factor analysis. Furthermore, the observed teams were categorised using all factor scores. Data were collected from 97 matches from the Spanish La Liga and the English Premier League from the seasons 2006-2007 and 2010-2011 using the Amisco ${ }^{\circledR}$ system. A total of 19 performance indicators, 14 describing aspects of attacking play and five describing aspects of defensive play, were included in the factor analysis. Six factors, representing 12 different styles of play (eight attacking and four defensive), had eigenvalues greater than 1 and explained $87.54 \%$ of the total variance. Direct and possession styles of play, defined by factor 1, were the most apparent styles. Factor analysis used the performance indicators to cluster each team's style of play. Findings showed that a team's style of play was defined by specific performance indicators and, consequently, teams can be classified to create a playing style profile. For practical implications, playing styles profiling can be used to compare different teams and prepare for opponents in competition. Moreover, teams could use specific training drills directed to improve their styles of play.

\section{Introduction}

Strategies and tactics are important factors that influence the outcome of the game and the final result in soccer (Yiannakos \& Armatas, 2006). A strategy is defined as the overall plan that is devised and adopted to achieve an aim or specific objective, and is normally accomplished via the application of specific tactics (Carling, Williams, \& Reilly, 2005). For example, soccer teams adopt an overall combination of attacking and defensive styles of play that would increase their probability of success. A style of play could be considered as the general behaviour of the whole team to achieve the attacking and defensive objectives in the game. Performance indicators are a selection of action variables that try to define the aspects of a performance (Hughes \& Bartlett, 2002) and can be associated with attacking and defensive tactics in soccer. Previous studies highlighted the influence of styles of play when measuring performance indicators related to physical (Buchheit \&

40 Laursen, 2013; Reilly, 2005), technical and tactical aspects in soccer (Bradley et al., 2011; Duarte, Araújo, Correia, \& Davids, 2012; James, Mellalieu, \& Hollely, 2002; Lago-Peñas, LagoBallesteros, \& Rey, 2011; Pollard \& Reep, 1997; Pollard, Reep, \& Hartley, 1988; Tenga, Holme, Ronglan, \& Bahr, 2010b; Tenga \& Sigmundstad, 2011). For instance, styles of play affect physical performance indicators such as distance covered by the players or high-intensity running activities, due to players' different movements as a result of specific behaviours typical of a style of play. Moreover, styles of play can also affect technical and tactical performance indicators such as
ARTICLE HISTORY

Accepted 17 March 2016

\section{KEYWORDS}

Association football; match analysis; tactics; factor analysis; Premier League; La Liga

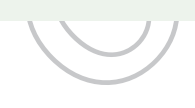

individual playing area (Fradua et al., 2013), percentage of ball possession (Lago \& Martín, 2007; Lago-Peñas \& Dellal, 2010), distance of passes and passing distribution (Tenga \& Larsen, 2003). These studies showed that styles of play should be accounted for during data interpretation.

Previous studies have identified attacking and defending styles of play. High pressure and low pressure have for example been defined as defending styles (Bangsbo \& Peitersen, 2000; Wright, Atkins, Polman, Jones, \& Sargeson, 2011). These two defending styles of play are characterised by the specific location on the pitch where teams apply defensive pressure on the opponent in possession, considering pressure as reducing the distance to player in possession and other near opponents in order to regain the ball as quickly as possible. For example, if defending players apply pressure in areas closer to the opponent's goal, they will be utilising the "high pressure" style. In contrast, the "low pressure" style of play involves the defensive players only applying pressure on the opponents in the defensive half of the pitch.

Attacking styles of play have previously been defined as direct, possession, counterattacking, total soccer and crossing (Bangsbo \& Peitersen, 2000; Pollard et al., 1988). "Direct" and "possession" styles of play are the most commonly described attacking styles (Bate, 1988; Garganta, Maia, \& Basto, 1997; Hughes \& Franks, 2005; Olsen \& Larsen, 1997; RedwoodBrown, 2008; Ruiz-Ruiz, Fradua, Fernández-Garcĺa, \& Zubillaga, 2013; Tenga, Holme, Ronglan, \& Bahr, 2010a; Tenga et al., 2010b; Tenga \& Larsen, 2003; Tenga, Ronglan, \& 
Bahr, 2010; Travassos, Davids, Araujo, \& Esteves, 2013). In contrast to "possession" style, "direct" play is characterised by longer passes, low number of passes, short passing sequences and a low number of touches per ball involvement. Game control was also a performance indicator associated with these styles of play, and was employed by a recent study that utilised indexes calculated from different performance indicators to evaluate the use of the possession and direct styles of play in elite teams (Kempe, Vogelbein, Memmert, \& Nopp, 2014). These indexes included several passing and ball possession parameters to measure tactical behaviour of teams. In addition, attacking styles such as "counterattacking play" (Bangsbo \& Peitersen, 2000), "total soccer" (Bangsbo \& Peitersen, 2000; Carling et al., 2005) and "crossing" (Pollard et al., 1988) have been defined but with no or little information on the key performance indicators for each of these styles.

A previous study that provided information on the performance indicators for different styles of play was a quantitative comparison between the styles of play used by English league teams during season 1984-1985, and national teams that played in the 1982 World Cup (Pollard et al., 1988). Six performance indicators were measured and factor analysis was used to define the different styles of play for the teams observed. The study identified three factors: factor 1 distinguished between direct and possession (elaborate) styles; factor 2 explained the use of crosses; finally, factor 3 made a distinction between a style that entails regaining the possession closer to the opponent's or own goal. Each team's dependence on a style was categorised on the basis of their factor score for the style of play.

Performance indicators associated with styles of play have been described in parts (Bate, 1988; Hughes \& Franks, 2005; Lago-Peñas \& Dellal, 2010; Pollard et al., 1988; Tenga et al., 2010b; Tenga \& Larsen, 2003); however, there is no consensus and/or missing information for some styles. For example, Tenga and Larsen (2003) describe direct play as attacks involving direct set plays, counter-attacks, attacks with at least one long pass, attacks with a maximum of two passes, and attacks moving fast over and through midfield. In contrast, Hughes and Franks (2005) consider low passing sequences as the key performance indicator for direct play. Previous research suggests that performance indicators for the different styles of play are unclear and that additional indicators should be examined to analyse styles of play. Hence, direction of passes and ball possession in different areas could be, for instance, important performance indicators when trying to identify styles of play. Moreover, additional defensive performance indicators should be considered such as areas where defending teams apply pressure, or time required to recover ball possession (Vogelbein, Nopp, \& Hökelmann, 2014). In addition, soccer involves an interaction between attack and defence (Moura et al., 2013), and this interaction makes it difficult to quantify team performance indicators and tactics without considering the opposition's ones. Consequently, attacking and defensive behaviours of teams should be measured to account for this interaction. The aim of the study was to define different styles of play in elite soccer and identify the associated performance indicators. A secondary aim was to classify the teams observed based on the styles so that a playing style profile can be created.

\section{Methods}

\section{Match sample}

A total sample of 97 matches from the Spanish La Liga and the English Premier League involving 37 different teams were collected for the study. Matches were monitored using a multiple camera match analysis system (Amisco Pro ${ }^{\circledR}$, version 1.0.2, Nice, France). From the total sample, 72 matches corresponded to season 2006-2007, 40 matches from the Spanish La Liga and 32 matches from the English Premier League. These two group of matches involved 18 and 15 different teams, respectively. Furthermore, 25 matches corresponded to season 2010-2011 and were from the Spanish La Liga. This group of matches involved 16 different teams.

Teams that participated in both seasons were considered as different teams due to possible changes in the squad and technical staff of each team. These changes can lead to a different style of play. Moreover, teams with only one match available were excluded from the analysis as it was considered that one match is not enough of a sample to define a team's style of play. Accordingly, 37 different teams were included in the analysis. From the overall sample, there were at least four matches available for 15 teams, three matches available for eight teams and two matches available for 14 teams. The present study follows the research ethics guidelines set out by Liverpool John Moores University.

\section{Procedure}

A total of 19 performance indicators (14 attacking and 5 defensive) were included in the study. Previous research relating to tactics was considered when selecting the following performance indicators for the study: possession of the ball (Jones, James, \& Mellalieu, 2004; Lago \& Martín, 2007), crosses (Lago-Peñas, LagoBallesteros, Dellal, \& Gomez, 2010; Pollard et al., 1988) and shots (Hughes \& Franks, 2005; Lago-Ballesteros \& Lago-Peñas, 2010; Pollard \& Reep, 1997). The remaining performance indicators, provided by the Amisco ${ }^{\circledR}$ system, were considered to be relevant to determine styles of play due to the importance of the spatial occurrence of the events for measuring tactical aspects (Castellano, Alvarez, Figueira, Coutinho, \& Sampaio, 2013). The attacking and defensive performance indicators, description and measurement methods are presented in Table 1. For the following performance indicators presented in Table 1: 2, 3, 4, 11, 12, 15 , 16 and 17; the pitch was divided into three spaces parallel to the goal lines to collect the data (see Figure 1). In addition, for the following performance indicators presented in Table 1: 5, 6, 18 and 19; the pitch was divided into three spaces parallel to the touchlines to collect the data (see Figure 1). Passing direction was also considered to measure the following performance indicators in Table 1: 7, 8, 9 and 10. Trajectories of passes were categorised according to the diagram in Figure 2.

For the analysis, a team mean score for each performance indicator was calculated and recorded using Microsoft Excel (Microsoft Corporation, Redmond, WA, USA). 
Table 1. Description and measurement of attacking and defensive performance indicators.

Attacking performance

indicators Description

1. Possession of the ball Percentage of time that the team has possession of the ball in the match.

2. Possession of the ball Percentage of time that the team has the possession of the ball in in the defensive third the defensive third of the pitch. of the pitch

3. Possession of the ball Percentage of time that the team has the possession of the ball in in the middle third of the middle third of the pitch from all the time that the team the pitch has the possession of the ball.

4. Possession of the ball Percentage of time that the team have the possession of the ball in the attacking third in the attacking third of the pitch (next to the opposite goal) of the pitch from all the time that the team have the possession of the ball.

5. Possession of the ball Percentage of time that the team has the possession of the ball in in the central areas the central areas of the pitch from all the time that the team of the pitch has the possession of the ball.

6. Possession of the ball Percentage of time that the team has the possession of the ball in in the wide areas of the wide areas of the pitch from all the time that the team has the pitch

7. Direction of passes the possession of the ball.

A rate that summarise the direction of the passes made by the team. As this number increases, the team tends to use more passes in the direction of the opposite goal.

8. Forwards passes

9. Sideways passes

10. Backwards passes

Percentage of passes from the overall number of passes made by the team that are made forwards (towards the opposite goal).

Percentage of passes from the overall number of passes made by the team that are made sideways.

Percentage of passes from the overall number of passes made by the team that are made backwards (towards the own goal).

11. Passes from defensive third to middle third

12. Passes from defensive third to attacking third

13. Crosses

14. Shots

Percentage of passes from the overall number of passes made by the team that are made from the defensive third (next to the own goal) to the middle third of the pitch.

Percentage of passes from the overall number of passes made by the team that are made directly from the defensive third (next to the own goal) to the attacking third of the pitch (next to the opposite goal).

Percentage of attacking sequences that finish with a cross in the opposing half from all the attacking sequences made by the team.

Percentage of attacking sequences that finish with a shot from all the attacking sequences made by the team.

Measurement

Possession of the ball for the team was collected separately for each half of the match as it is provided by the Amisco system. The average from the possession of the two halves for each team was calculated.

These performance indicators were calculated by taking the overall time that the team had the possession of the ball and the time that the team had the possession of the ball in the area corresponding to the performance indicator. Hence the percentage (normalised data) was calculated from these data provided by the Amisco system.

A score of one was given to the backwards passes, a score of two was given to the sideways passes, and a score of three was given to the forwards passes. The mean of the scores of all the passes made by the team were calculated.

The Amisco system provided the direction of the movements of the ball by looking at the point where the pass started and the point where the pass was received. Consequently, depending of the trajectory of the ball the pass was categorised following the diagram showed in Figure 2. Data was normalised by calculating the percentage of these passes according to the total number of passes made by the team.

These performance indicators were measured by calculating the percentage of these kinds of passes from the overall amount of passes made by the team in the match.

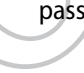

Data provided by the Amisco System was collected and normalised by calculating the percentage from all of these events made by a team during the whole match.

\begin{tabular}{|c|c|}
\hline e & Description \\
\hline $\begin{array}{l}\text { 15. Regains in the } \\
\text { defensive third }\end{array}$ & $\begin{array}{l}\text { Percentage of the number of times that the team regains the bal } \\
\text { the defensive third (next to own goal) from all the regains ma } \\
\text { by the team. }\end{array}$ \\
\hline $\begin{array}{l}\text { 16. Regains in the } \\
\text { middle third }\end{array}$ & $\begin{array}{l}\text { Percentage of the number of times that the team regains the ball } \\
\text { in the middle third from all the regains made by the team. }\end{array}$ \\
\hline $\begin{array}{l}\text { 17. Regains in the } \\
\text { attacking third }\end{array}$ & $\begin{array}{l}\text { Percentage of the number of times that the team regains the ball } \\
\text { in the attacking third (next to opposite goal) from all the regains } \\
\text { made by the team. }\end{array}$ \\
\hline $\begin{array}{l}\text { 18. Regains in the } \\
\text { central areas } \\
\text { of the pitch }\end{array}$ & $\begin{array}{l}\text { Percentage of the number of times that the team regains the ball } \\
\text { in the middle areas of the pitch from all the regains made by } \\
\text { the team. }\end{array}$ \\
\hline $\begin{array}{l}\text { 19. Regains in the } \\
\text { wide areas of } \\
\text { the pitch }\end{array}$ & $\begin{array}{l}\text { Percentage of the number of times that the team regains the ball } \\
\text { in the wide areas of the pitch from all the regains made by the } \\
\text { team. }\end{array}$ \\
\hline
\end{tabular}

\section{Statistical analysis}

Exploratory factor analysis using principal component analysis (PCA) was conducted on 19 performance indicators with orthogonal rotation (varimax). Factor analysis is a statistical method for identifying clusters of variables. This technique allows the reduction of data sets into factors through the grouping of variables measured (Field, 2013). For each factor, the performance indicators with the highest factor loading (i.e., the correlation between the performance indicator and the factor) were identified. This technique groups performance indicators into fewer factors that represent different styles of play. In addition, a team's specific style of play can be categorised according to their score for each factor. Statistical analysis was carried out using IBM SPSS Statistics v.20.0 for Windows (SPSS, Chicago, IL USA).

Orthogonal (varimax) and oblique rotations were performed in factor analysis and the component correlation matrix of the oblique rotation showed a negligible correlation between factors, therefore orthogonal rotation was used
These performance indicators were calculated by taking the total number of times that the team regained the possession of the ball and the number of times that the team regained the possession of Hence the percentage (normalised data) was calculated from these data provided by the Amisco system. 


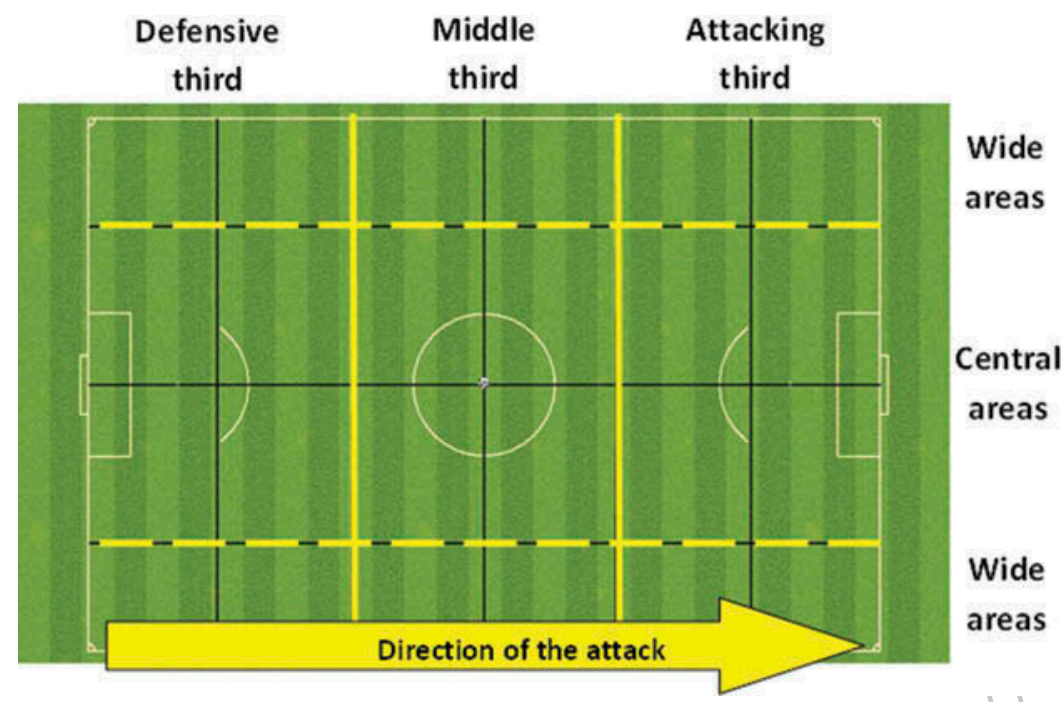

Figure 1. Pitch divisions in three thirds parallel to the goal lines and parallel to the touchlines.

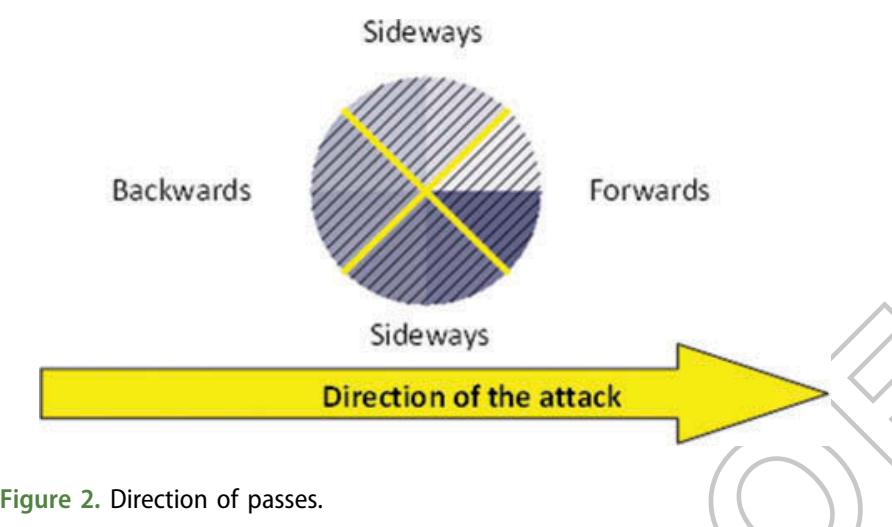

(Pedhazur \& Schmelkin, 1991). The Kaiser-Meyer-Olkin measure (Kaiser, 1974) and communalities values after extraction (MacCallum, Widaman, Zhang, \& Hong, 1999) were employed to verify the sampling adequacy for the analysis. Adequacy of correlations between items was done according to Bartlett's test of sphericity. Kaiser's criterion of 1 (Kaiser, 1960) and interpretation of the scree plot were considered for factor retention. Performance indicators with factor loadings greater than $|0.7|$ showed a strong positive or negative correlation and indicated a substantial value for factor interpretation (Comrey \& Lee, 2013).

\section{Results}

The Kaiser-Meyer-Olkin (KMO) measure verified the sampling adequacy for the analysis, $\mathrm{KMO}=0.53$, and the communalities after extraction were greater than 0.7 in 18 of 19 performance indicators, deeming sample size to be adequate for factor analysis. Bartlett's test of sphericity $\left(X^{2}=2254.53, \mathrm{df}=171\right.$, $P<0.001)$ indicated that correlations between items were sufficiently large for PCA. Six components had eigenvalues over Kaiser's criterion of 1 and in combination explained $87.54 \%$ of the total variance (Table 2). The percentage of variance explained by each factor decreased from factor 1 to 6 . The scree plot was slightly ambiguous and showed inflexion points that would justify retaining four or six factors. Therefore, six factors were extracted following the Kaiser's criterion as the number of performance indicators was less than 30 and communalities after extraction were greater than 0.7 (Stevens, 2009). The rotated component matrix for the factor loadings identified the performance indicators associated with each factor (Table 3).

Descriptions of factors were interpreted based on the group of associated performance indicators. Factor 1 (possession directness) defines how direct a team's possession is. A team with a positive score in this factor tends to use a direct (D) style. In contrast, a team with a negative score adopts a more elaborate, possession (P) style. Factor 2 (width of ball regain) defines teams that pressure and regain the ball in wide areas (PW) or in the central areas (PC) of the pitch. A team with a positive score regain more balls close to the touchline, whereas a team with a negative score regain more balls in the central areas. Factor 3 (use of crosses) distinguish between crossing (C) and no crossing (NC) styles. This factor defines a team's use of crosses and how much possession of the ball they have in the defensive third. These performance indicators correlate highly, consequently a team that scores positively on this factor have a higher percentage of possession in the defensive third and use crosses to finish the attack. Factor 4 (possession width) defines teams that tend to play in wider areas of the pitch using a wide possession (WP) style if they score positively on this factor. In contrast, teams that score negatively tend to use central areas of the pitch to develop the attack using a narrow possession (NP) style. Factor 5 (defensive ball pressure) defines teams that use a high- or low-pressure style of play. A positive score defines a lowpressure (LP) style, whereas a negative score defines a highpressure (HP) style. Finally, a positive score on factor 6 (progression of the attack) defines teams that employ a fast progression (FP) style and usually progress straight to the opponent's goal, whereas negative scoring teams utilise a slow progression (SP) and tend to use more maintenance passes to supporting players behind the position of the ball to look for better options to progress to the opponent's goal. 
Table 2. Eigenvalues for components and total variance explained.

\begin{tabular}{|c|c|c|c|c|c|c|c|c|c|}
\hline \multirow[b]{2}{*}{ Component } & \multicolumn{3}{|c|}{ Initial eigenvalues } & \multicolumn{3}{|c|}{ Extraction sums of squared loadings } & \multicolumn{3}{|c|}{ Rotation sums of squared loadings } \\
\hline & Total & $\%$ of Variance & Cumulative \% & Total & $\%$ of Variance & Cumulative \% & Total & $\%$ of Variance & Cumulative \% \\
\hline 1 & 7.043 & 37.069 & 37.069 & 7.043 & 37.069 & 37.069 & 5.281 & 27.795 & 27.795 \\
\hline 2 & 3.243 & 17.069 & 54.138 & 3.243 & 17.069 & 54.138 & 2.796 & 14.718 & 42.513 \\
\hline 3 & 2.402 & 12.640 & 66.778 & 2.402 & 12.640 & 66.778 & 2.777 & 14.617 & 57.130 \\
\hline 4 & 1.749 & 9.208 & 75.986 & 1.749 & 9.208 & 75.986 & 2.631 & 13.849 & 70.979 \\
\hline 5 & 1.159 & 6.098 & 82.083 & 1.159 & 6.098 & 82.083 & 1.879 & 9.890 & 80.869 \\
\hline 6 & 1.036 & 5.453 & 87.536 & 1.036 & 5.453 & 87.536 & 1.267 & 6.667 & 87.536 \\
\hline 7 & 0.687 & 3.617 & 91.153 & & & & & & \\
\hline 8 & 0.512 & 2.695 & 93.849 & & & & & & \\
\hline 9 & 0.410 & 2.156 & 96.004 & & & & & & \\
\hline 10 & 0.312 & 1.644 & 97.648 & & & & & & \\
\hline 11 & 0.242 & 1.276 & 98.924 & & & & & & \\
\hline 12 & 0.125 & 0.658 & 99.582 & & & & & & \\
\hline 13 & 0.068 & 0.355 & 99.938 & & & & & & \\
\hline 14 & 0.011 & 0.060 & 99.998 & & & & & & \\
\hline 15 & 0.000 & 0.002 & 100.000 & & & & & & \\
\hline 16 & 0.000 & 0.000 & 100.000 & & & & & & \\
\hline 17 & 0.000 & 0.000 & 100.000 & & & & & & \\
\hline 18 & 0.000 & 0.000 & 100.000 & & & & & & \\
\hline 19 & 0.000 & 0.000 & 100.000 & & & & & & \\
\hline
\end{tabular}

\begin{tabular}{|c|c|c|c|c|c|c|}
\hline & 1 & 2 & & 4 & 5 & 6 \\
\hline Number of sideways passes $\%$ & -0.947 & 0.084 & 0.027 & 0.022 & -0.164 & 0.126 \\
\hline Number of forward passes $\%$ & 0.945 & -0.092 & -0.065 & 0.036 & 0.179 & 0.102 \\
\hline Average direction of passes & 0.882 & -0.115 & -0.094 & 0.102 & 0.174 & 0.309 \\
\hline Possession \% & -0.858 & 0.185 & 0.207 & -0.154 & -0.192 & 0.136 \\
\hline Passes from defensive to attacking third \% & 0.696 & -0.396 & -0.034 & 0.174 & -0.128 & 0.257 \\
\hline Number of shots $\%$ attacking sequences & -0.640 & 0.170 & 0.461 & -0.250 & 0.238 & 0.221 \\
\hline Number regains wide areas $\%$ & -0.253 & 0.937 & -0.052 & 0.093 & -0.103 & -0.016 \\
\hline Number regains central areas \% & 0.325 & -0.905 & 0.041 & -0.120 & 0.126 & 0.018 \\
\hline Number regains middle third \% & 0.131 & 0.602 & -0.116 & -0.599 & -0.319 & 0.158 \\
\hline Possession $\%$ middle third & 0.072 & 0.156 & -0.930 & 0.123 & 0.152 & -0.004 \\
\hline Possession \% defensive third & & -0.168 & 0.869 & -0.352 & -0.175 & -0.078 \\
\hline Number of crosses \% attacking sequences finish opposing half & -0.179 & 0.133 & 0.806 & 0.095 & -0.003 & -0.190 \\
\hline Possession \% attacking third & 0.049 & 0.121 & -0.319 & 0.787 & 0.155 & 0.255 \\
\hline Possession \% central areas & & -0.030 & 0.107 & -0.701 & 0.155 & -0.109 \\
\hline Possession $\%$ wide areas & 588 & 0.030 & -0.108 & 0.701 & -0.154 & 0.109 \\
\hline Number regains attacking third \% & -0.132 & 0.160 & 0.148 & 0.201 & -0.759 & -0.123 \\
\hline Passes from defensive to middle third \% & 0.365 & -0.110 & -0.208 & 0.322 & 0.672 & 0.027 \\
\hline Number regains defensive third \% & -0.056 & -0.603 & 0.036 & 0.436 & 0.625 & -0.083 \\
\hline Number of backwards passes \% & -0.070 & -0.015 & 0.168 & -0.191 & -0.091 & -0.913 \\
\hline
\end{tabular}

Factor loadings in bold showed a strong positive or negative correlation.

These factors can be plotted in different combinations to visually represent team styles, where the location of an individual team on the axes describes how much they adopt that playing style. For example, the team scores for factor 1 are plotted against the scores for the other attacking factors (see Figure 3(A)-C). Factor 1 was used to plot against the other factors because it explained the highest amount of variance (27.8\%). In addition, team scores for the defensive factors 2 and 5 are plotted in Figure 3(D).

\section{Discussion}

Defining different styles of play that soccer teams can adopt during a match may be important when analysing performance data. Therefore, the aim of the study was to identify and define the styles of play in elite soccer. Exploratory factor analysis extracted six factors that defined 12 different playing styles, split into eight attacking and four defending styles. Each factor defined two different styles of play based on a positive or negative factor score on the continuum. Furthermore, a team's score on each factor indicates their reliance on that specific style of play (see Table 4).

Possession directness (factor 1) explained the highest percentage of variance and differentiates the previously reported direct and possession styles (Bate, 1988; Garganta et al., 1997; Hughes \& Franks, 2005; Olsen \& Larsen, 1997; RedwoodBrown, 2008; Ruiz-Ruiz et al., 2013; Tenga et al., 2010a, 2010b; Tenga \& Larsen, 2003; Tenga et al., 2010; Travassos et al., 2013). "Sideways passes" and "possession of the ball" were the performance indicators that correlated negatively with this factor and suggested a possession style. The indicators that correlated positively and suggested a direct style were "possession of the ball" and "sideways passes". The performance indicator "passes from defensive to attacking third" was also included for direct style of play interpretation as it showed a high positive score loading for factor 1. During season 2010-2011, Barcelona showed a considerable high score for possession style of play (see Table 4). This team 

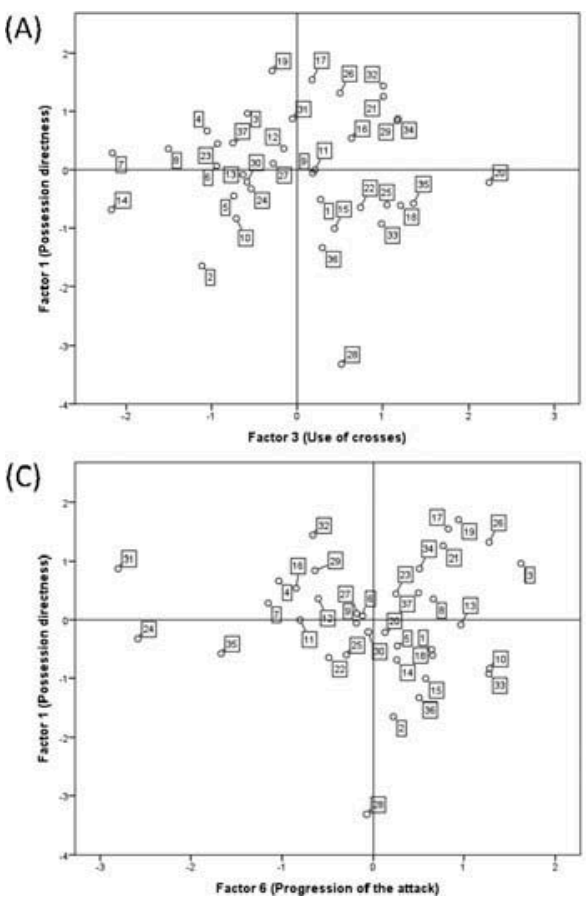

(B)

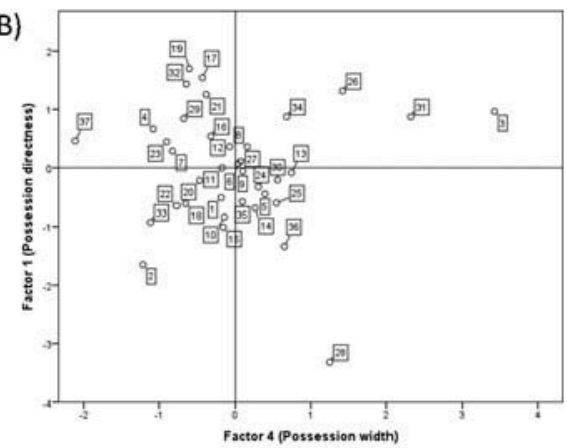

(D)

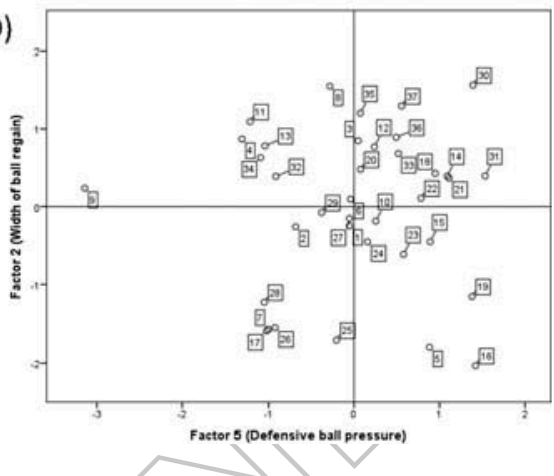

Figure 3. Styles of play of soccer teams according to factors. Attacking styles of play: (A) factor 1 and factor 3 , (B) factor 1 and factor 4 , (C) factor 1 and factor 6. Defensive styles of play: (D) factor 2 and factor 5 .

demonstrates a good representation of the possession style and it may be due to their playing philosophy and the highly skilled players in the team for passing abilities. It is suggested that the tactical principle of playing sideways causes imbalances in the opposition's defence, therefore increasing the success of the attacking sequence and the opportunity to score a goal (Tenga et al., 2010a, 2010b; Tenga et al., 2010; Tenga \& Sigmundstad, 2011). Previously, a direct style was described as being more advantageous than the possession style (Bate, 1988; Garganta et al., 1997). However, Hughes and Franks (2005) stated that, for successful teams, possession style produced more goals per possession than the direct style. In comparison, Tenga et al. (2010a) reported no difference in goals scored between these styles. Possibly, the long and short passing abilities and skill of players influence the effectiveness of a direct or possession style. Moreover, opponent's defensive style of play can also have an impact on the team's direct or possession style.

Factor 2 differentiates two defensive styles; a style of play that implies regaining the ball close to the touchline, and a style where ball is regained in the central areas of the pitch. These styles have not been reported previously. Styles of play differentiated by factor 2 are associated with the performance indicators "regains in the central areas of the pitch" and "regains in the wide areas of the pitch". Negative values for the former and positive values for the latter determine where the team regains the ball. Wright et al. (2011) reported that central ball regains are more likely to result in a scoring attempt compared to wide ball regains. In addition, recent studies showed successful teams normally regain the ball in central areas of the defensive and middle third (Barreira, Garganta, Guimaraes, Machado, \& Anguera, 2014; Barreira, Garganta, Machado, \& Anguera, 2014). This could possibly be because central areas provide different options of passing to the sides or forwards, whereas regaining the ball in the sides limit passing options due to the touchline. Furthermore, the utilisation of these styles could depend on team formation (number of players per area), player defensive abilities and/or the opponent's attacking abilities. Attacking styles of play of the opposition can also influence the defensive style of play employed by the team. Although the defensive team can lead the opposition players to specific areas of the pitch for conducting an attack (e.g., accumulating players in central areas and leaving free spaces on the sides for doing pressure to opposition in wide areas), a prevalence of an attacking style of play used by the opposition can affect the defensive style employed by the team.

Factor 3 defines two styles based on percentage of possession in the defensive third (i.e., time that the team control the ball near their own goal) combined with the use of crosses. Correlation between these indicators could suggest that teams using crossing might have more ball possession in the defensive third so that wide players have time to move into wide areas and execute a cross. Crossing is a tactic to create the chance of scoring (Ensum, Pollard, \& Taylor, 2005; Hughes \& Churchill, 2005; Konstadinidou \& Tsigilis, 2005; Lago-Peñas et al., 2010, 2011; Oberstone, 2009; Pollard, Ensum, \& Taylor, 2004); however, increases in scoring efficiency are not reported consistently (Flynn, 2001). Crossing can also be a risk due to the possibility of losing the ball and produce a counter-attacking opportunity for opponents. Use of crosses might be more effective for teams that adopt this style and have wide midfielders that employ long passing, strikers that create space in the penalty area, win aerial challenges and shot at goal with one touch (Carling et al., 2005; Ruiz-Ruiz et al., 2013). Moreover, this style could be useful when the opposition lacks aerial abilities, as the probability of taking advantage of their mistakes would be increased. 


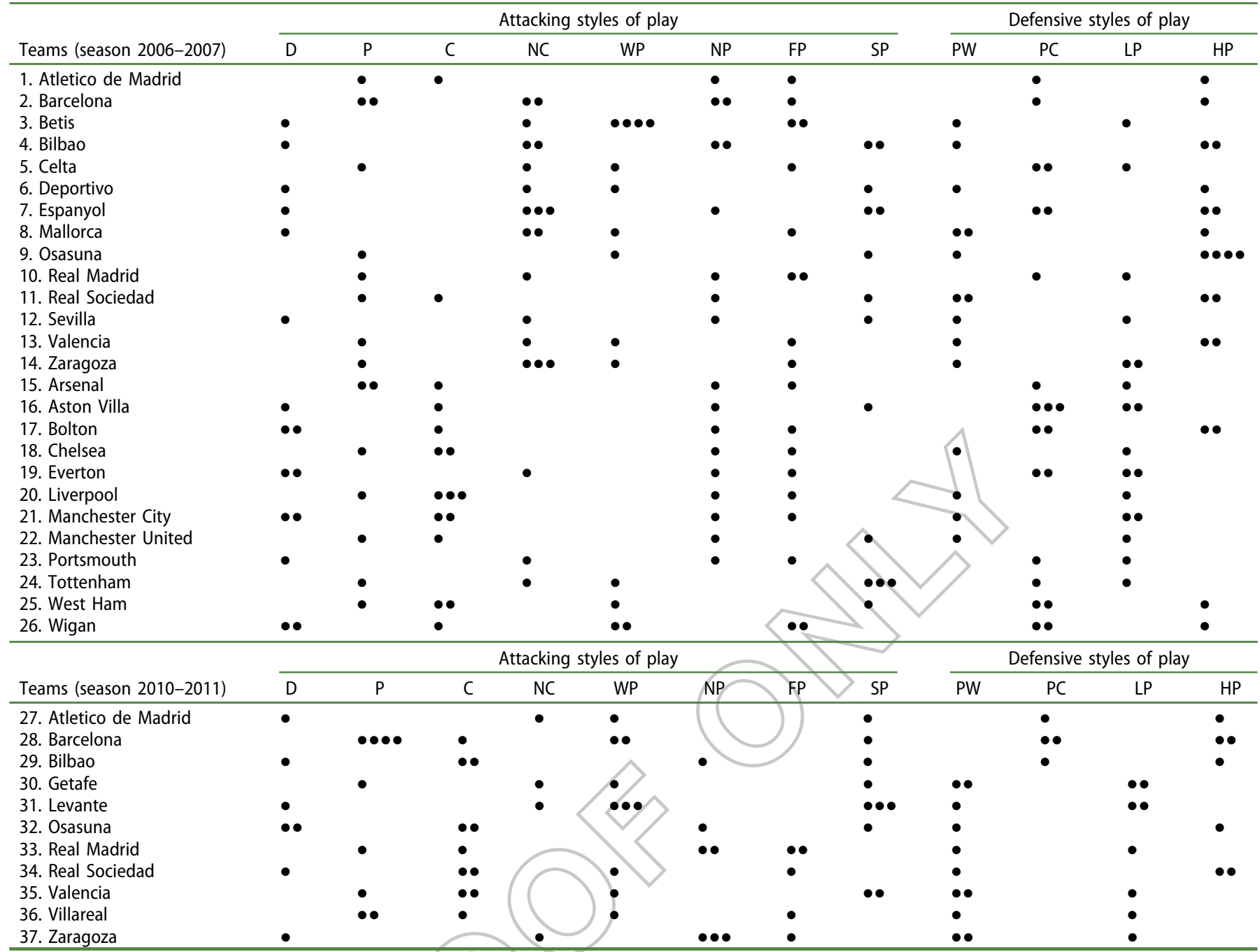

Abbreviations for attacking and defensive styles of play: Direct (D), Possession (P), Crossing (C), No Crossing (NC), Wide Possession (WP), Narrow Possession (NP), Fast Progression (FP), Slow Progression (SP), Pressure on Wide Areas (PW), Pressure on Central Areas (PC), Low Pressure (LP) and High Pressure (HP). The number of dots indicates the degree of utilisation of the style of play by the team, more dots indicates a higher utilisation.

- Score between 0 and \pm 1 . $\bullet$ Score between \pm 1 and \pm 2 . $\bullet \bullet$ Score between \pm 2 and \pm 3 . $\bullet \bullet \bullet$ Score between \pm 3 and \pm 4 .

Possession width (factor 4), suggest the differentiation between wide and narrow possession styles. These styles are associated with the percentage of ball possession teams have in central or wide areas; however, it does not necessarily mean that they play wide or narrow in their attacking sequences. "Possession of the ball in the attacking third of the pitch", "possession of the ball in the central areas of the pitch" and "possession of the ball in the wide areas of the pitch" are the performance indicators associated with this factor. The former performance indicator correlated highly with the latter, which could be due to easier maintenance of ball possession in attacking third wide areas compared to central areas. However, central areas could be larger in surface, so caution should be applied when interpreting this playing style. Moreover, due to the goal position, percentage of possession in central areas could be influenced. Betis was the team, during season 2006-2007, that relied the most on a wide possession style (see Table 4). The position of skilled players on the sides of the pitch and the use of playing formations that accumulated players in these areas could explain the high score of this team for this style. Attacking third central areas are dangerous for defensive teams and result in more attempts at goal, therefore defensive actions will be more intense (Pollard \& Reep, 1997; Ruiz-Ruiz et al., 2013; Scoulding, James, \& Taylor, 2004; Tenga et al., 2010; Wright et al., 2011; Yiannakos \& Armatas, 2006). For example, British soccer teams (2001-2002) had more ball entries into central (60.3\%) compared to wide (39.7\%) areas (James et al., 2002). Moreover, Hughes, Robertson, and Nicholson (1988) suggested that successful teams have more possession in the central compared to wide areas. The use of a wide or narrow possession style will probably depend on the abilities of the wide and central players of the team. For example, teams with skilled wide midfielders and/or fullbacks would utilise the wide possession style of play due to the abilities of these players for maintaining ball possession. Opponent's defensive style of play could also influence the use of narrow or wide possession style.

Factor 5 identifies teams that use high- or low-pressure defensive styles of play. "Number of regains in the attacking third" was the performance indicator that correlated negatively with this factor. Moreover, "passes from defensive to middle third" also 
had a high positive score loading for this factor, and this could suggest that teams that move the ball from defensive to middle third to build the attack, tend to regain the ball in these areas. In season 2006-2007, Osasuna was the team that employed the high-pressure style in the most emphasised way (see Table 4). A high-pressure style could cause a risky situation for the defensive team due to the space produced behind the defensive players or the space between players in case that the team failed to keep compactness. However, it can also influence scoring opportunities because the ball can be regained closer to the opponent's goal, while increasing the likelihood of facing an imbalanced defence (Bell-Walker, McRobert, Ford, \& Williams, 2006; Garganta et al., 1997; Grant, Williams, Reilly, \& Borrie, 1998; Pollard \& Reep, 1997; Russell, 2006; Scoulding et al., 2004; Wright et al., 2011). Successful teams from European Leagues and World Cups tend to have higher attacking third regains (BellWalker et al., 2006; Garganta et al., 1997). Moreover, Tenga et al. (2010a) reported that the probability of producing a score-box possession decreases when a balanced defence is present (i.e., defenders provide defensive backup and cover). The utilisation of high- or low-pressure styles could be notably influenced by the opposing team's style of play (Cotta, Mora, Merelo-Molina, \& Merelo, 2013). For instance, using a high-pressure style of play against a team that utilises a possession style of play could be very effective for regaining the ball due to time and space denied to attacking players, while increasing the chances of scoring opportunities.

Factor 6 describes team progression towards the opponent's goal; however, it accounts for the lowest percentage of variance $(6.67 \%)$. The use of backward passes moves the ball further from the opponent's goal; therefore, an increase in backwards passes is more likely to increase the time taken to reach the opponent's goal. For this reason, a high quantity of backwards passes could suggest a slow progression of possession. In contrast, fewer backward passes would suggest a fast progression of possession. These styles are not mentioned in previous studies, and the only performance indicator associated with factor 6 (i.e., "backwards passes") makes it complex to explain. The progression of the possession factor could be associated with the directness; however, it is different. When using backwards passes the team tries to secure or support ball possession by passing the ball to a less advanced teammate to create space and new opportunities to attack. For example, a team that uses a direct style might also use backwards passes to create a new opportunity for scoring. This team would have a slow progression but also score high on possession directness (e.g., Bilbao in both seasons 2006-2007 and 2010-2011).

A secondary aim was to classify the team's styles so that playing style profiles could be created for each team. Positive or negative scores for the six factors would determine how much a team relies on one specific style or combination of these styles. For example, in season 2006-2007, Everton used the direct, no crossing, narrow and fast progression styles of play in attack. In defence they used a low-pressure style while applying pressure in central areas to regain the ball. Everton's high score on factor 1 defines a direct style in attack due to the team's high percentage of forward passes, low percentage of sideways passes and possession of the ball. In contrast, during the 2006-2007 season, Barcelona applied pressure in central areas and used high-pressure defensive styles, combined with possession, no crossing, narrow and fast progression attacking styles. Barcelona scored high on the percentage of regains in the attacking third, which is one of the performance indicators that define the high-pressure style. Moreover, during the 2010-2011 season, Barcelona adopted alternative styles and intensified the use of previously used styles. They used the crossing, wide and slow progression attacking styles, and increased their factor scores for the possession attacking style, pressure in central areas and highpressure defensive styles, compared to the 2006-2007 season. These individual examples highlight how a team uses specific attacking and defensive styles of play in a season. Moreover, in the case of Barcelona it highlights changes that occur in the styles of play across two separate seasons, which could be due to the tactical management of the coach and the players.

In conclusion, 12 (eight attacking and four defensive) different playing styles and associated performance indicators utilised in elite soccer were identified in this data set. Furthermore, the selected factors together explained $87.54 \%$ of the variance. The degree to which a team relies on a specific style can be determined based on the team's score for each factor. Findings from this study have several practical implications for performance analysis. First, teams can objectively determine the styles they use and their reliance on specific styles to create playing style profiles and normative profiles for associated performance indicators. These profiles can be used to benchmark team's performance during competition or alternatively adjust their styles based on reference values they wish to adopt. Furthermore, teams could use specific training drills to develop styles that they will employ in competition while using the associated performances indicators to monitor change. Second, playing styles profiling can be used on opponents to identify their dominant styles and benchmark their performance indicators. This data could be used to prepare tactics that would perturb the opponent's dominant style(s) and identify strengths and weaknesses of the opposition. Third, recruitment analysts could introduce playing styles profiling into their analysis framework when identifying individual players that they wish to integrate into the team. Finally, previous research provided contradictory evidence when measuring performance indicators associated with success in isolation of factors (i.e., style of play, home advantage, type of competition, quality of opponents and quality of team) that might affect the value. Therefore, differences in performance indicators might be a factor of their playing styles. Researchers should be aware of these different styles and may integrate this into their analysis. Limitations of this study should be noted. Contextual variables (e.g., playing home/away, opposition level) were not measured and these variables could affect styles of play used by teams. These variables could also explain the missed percentage of the variance. Moreover, interaction process should be considered for a more accurate analysis of styles of play as opponent's tactics can also influence the style of play employed by a team. This study provides an introduction to analysing playing styles. More variables and matches should be considered to supply conclusive definitions for playing styles and generalisability of the data. Further research should attempt to establish the efficiency and effectiveness of playing styles when measuring performance and outcomes (i.e., scoring probability). 


\section{Disclosure statement}

No potential conflict of interest was reported by the authors.

\section{ORCID}

Javier Fernandez-Navarro (D) http://orcid.org/0000-0002-5367-1575

\section{References}

Bangsbo, J., \& Peitersen, B. (2000). Soccer systems and strategies. Champaign, IL: Human Kinetics.

Barreira, D., Garganta, J., Guimaraes, P., Machado, J., \& Anguera, M. T. (2014). Ball recovery patterns as a performance indicator in elite soccer. Proceedings of the Institution of Mechanical Engineers, Part P: Journal of Sports Engineering and Technology, 228(1), 61-72.

Barreira, D., Garganta, J., Machado, J., \& Anguera, M. T. (2014). Effects of ball recovery on top-level soccer attacking patterns of play. [Repercussoes da recuperacao da posse de bola nos padroes de ataque de futebol de elite]. Revista Brasileira de Cineantropometria \& Desempenho Humano, 16(1), 36-46.

Bate, R. (1988). Football chance: Tactics and strategy. In T. Reilly, A. Lees, K. Davids, \& W. J. Murphy (Eds.), Science and football (pp. 293-301). London: E \& FN Spon.

Bell-Walker, J., McRobert, A., Ford, P., \& Williams, A. M. (2006). A quantitative analysis of successful teams at the 2006 World Cup Finals. Insight: The FA Coaches Association Journal, Autumn/Winter, 36-43.

Bradley, P. S., Carling, C., Archer, D., Roberts, J., Dodds, A., Di Mascio, M., ... Krustrup, P. (2011). The effect of playing formation on high-intensity running and technical profiles in English FA Premier League soccer matches. Journal of Sports Sciences, 29(8), 821-830.

Buchheit, M., \& Laursen, P. B. (2013). High-intensity interval training, solutions to the programming puzzle part I: Cardiopulmonary emphasis. Sports Medicine, 43(5), 313-338.

Carling, C., Williams, A. M., \& Reilly, T. (2005). Handbook of soccer match analysis. A systematic approach to improving performance, London: Routledge.

Castellano, J., Alvarez, D., Figueira, B., Coutinho, D., \& Sampaio, J. (2013). Identifying the effects from the quality of opposition in a Football team positioning strategy. International Journal of Performance Analysis in Sport, 13(3), 822-832.

Comrey, A. L., \& Lee, H. B. (2013). A first course in factor analysis (2nd ed.). Hillsdale, NJ: Erlbaum.

Cotta, C., Mora, A. M., Merelo-Molina, J. J., \& Merelo, C. (2013). A network analysis of the 2010 FIFA world cup champion team play. Journal of Systems Science \& Complexity, 26(1), 21-42.

Duarte, R., Araújo, D., Correia, V., \& Davids, K. (2012). Sports teams as superorganisms implications of sociobiological models of behaviour for research and practice in team sports performance analysis. Sports Medicine, 42(8), 633-642.

580 Ensum, J., Pollard, R., \& Taylor, S. (2005). Applications of logistic regression to shots at goal in association football. In T. Reilly, J. Cabri, \& D. Araujo (Eds.), Science and football V (pp. 211-218). London: Routledge.

Field, A. (2013). Discovering statistics using IBM SPSS statistics (4th ed.). London: SAGE Publications.

Flynn, T. (2001). The effects of crosses across three levels of professional football. Insight: The F.A. Coaches Association Journal, 4(2), 13-16.

Fradua, L., Zubillaga, A., Caro, O., Fernandez-Garcia, A. I., Ruiz-Ruiz, C., \& Tenga, A. (2013). Designing small-sided games for training tactical aspects in soccer: Extrapolating pitch sizes from full-size professional matches. Journal of Sports Sciences, 31(6), 573-581.

Garganta, J., Maia, J., \& Basto, F. (1997). Analysis of goal-scoring patterns in European top level soccer teams. In J. Bangsbo, T. Reilly, \& A. M. Williams (Eds.), Science and football III (pp. 246-250). London: E \& FN Spon.

Grant, A., Williams, A. M., Reilly, T., \& Borrie, A. (1998). Analysis of the successful and unsuccessful teams in the 1998 World Cup. Insight: The F.A. Coaches Association Journal, 2(1), 21-24.

Hughes, M., \& Bartlett, R. (2002). The use of performance indicators in performance analysis. Journal of Sports Sciences, 20(10), 739-754.
Hughes, M., \& Churchill, S. (2005). Attacking profiles of successful and unsuccessful teams in Copa America 2001. In T. Reilly, J. Cabri, \& D. Araujo (Eds.), Science and football V (pp. 221-224). London: Routledge.

Hughes, M., \& Franks, I. (2005). Analysis of passing sequences, shots and goals in soccer. Journal of Sports Sciences, 23(5), 509-514.

Hughes, M., Robertson, K., \& Nicholson, A. (1988). Comparison of patterns of play of successful and unsuccessful teams in the 1986 World Cup for soccer. In T. Reilly, A. Lees, K. Davids, \& W. J. Murphy (Eds.), Science and football (pp. 363-367). London: E \& FN Spon.

James, N., Mellalieu, S. D., \& Hollely, C. (2002). Analysis of strategies in soccer as a function of European and domestic competition. International Journal of Performance Analysis in Sport, 2(1), 85-103.

Jones, P. D., James, N., \& Mellalieu, S. D. (2004). Possession as a performance indicator in soccer. International Journal of Performance Analysis in Sport, 4(1), 98-102.

Kaiser, H. F. (1960). The application of electronic computers to factor analysis. Educational and Psychological Measurement, 20(1), 141-151.

Kaiser, H. F. (1974). An index of factorial simplicity. Psychometrika, 39(1), 31-36.

Kempe, M., Vogelbein, M., Memmert, D., \& Nopp, S. (2014). Possession vs. direct play: Evaluating tactical behavior in Elite Soccer. International Journal of Sports Science, 4(6A), 35-41.

Konstadinidou, X., \& Tsigilis, N. (2005). Offensive playing profiles of football teams from the 1999 Women's World Cup Finals. International Journal of Performance Analysis in Sport, 5(1), 61-71.

Lago, C., \& Martín, R. (2007). Determinants of possession of the ball in soccer. Journal of Sports Sciences, 25(9), 969-974.

Lago-Ballesteros, J., \& Lago-Peñas, C. (2010). Performance in team sports: Identifying the keys to success in Soccer. Journal of Human Kinetics, 25 , 85-91.

Lago-Peñas, C., \& Dellal, A. (2010). Ball possession strategies in Elite Soccer according to the evolution of the match-score: The influence of situational variables. Journal of Human Kinetics, 25, 93-100.

Lago-Peñas, C., Lago-Ballesteros, J., Dellal, A., \& Gomez, M. (2010). Gamerelated statistics that discriminated winning, drawing and losing teams from the Spanish soccer league. Journal of Sports Science and Medicine, 9(2), 288-293.

Lago-Peñas, C., Lago-Ballesteros, J., \& Rey, E. (2011). Differences in performance indicators between winning and losing teams in the UEFA Champions League. Journal of Human Kinetics, 27, 137-148.

MacCallum, R. C., Widaman, K. F., Zhang, S. B., \& Hong, S. H. (1999). Sample size in factor analysis. Psychological Methods, 4(1), 84-99.

Moura, F. A., Martins, L. E. B., Anido, R. O., Ruffino, P. R. C., Barros, R. M. L., \& Cunha, S. A. (2013). A spectral analysis of team dynamics and tactics in Brazilian football. Journal of Sports Sciences, 31(14), 1568-1577.

Oberstone, J. (2009). Differentiating the top English Premier League football clubs from the rest of the pack: Identifying the keys to success. Journal of Quantitative Analysis in Sports, 5(3). doi:10.2202/15590410.1183

Olsen, E., \& Larsen, O. (1997). Use of match analysis by coaches. In J. Bangsbo, T. Reilly, \& A. M. Williams (Eds.), Science and football III (pp. 209-220). London: E \& FN Spon.

Pedhazur, E. J., \& Schmelkin, L. P. (1991). Measurement, design, and analysis: An integrated approach. Hillsdale, NJ: Erlbaum.

Pollard, R., Ensum, J., \& Taylor, S. (2004). Estimating the probability of a shot resulting in a goal: The effects of distance, angle and space. International Journal of Soccer and Science, 2(1), 50-55.

Pollard, R., \& Reep, C. (1997). Measuring the effectiveness of playing strategies at Soccer. Journal of the Royal Statistical Society: Series $D$ (The Statistician), 46(4), 541-550.

Pollard, R., Reep, C., \& Hartley, S. (1988). The quantitative comparison of playing styles in soccer. In T. Reilly, A. Lees, K. Davids, \& W. J. Murphy (Eds.), Science and football (pp. 309-315). London: E \& FN Spon.

Redwood-Brown, A. (2008). Passing patterns before and after goal scoring in FA Premier League Soccer. International Journal of Performance Analysis in Sport, 8(3), 172-182.

Reilly, T. (2005). An ergonomics model of the soccer training process. Journal of Sports Sciences, 23(6), 561-572.

Ruiz-Ruiz, C., Fradua, L., Fernández-Garcĺa, Á., \& Zubillaga, A. (2013). Analysis of entries into the penalty area as a performance indicator in soccer. European Journal of Sport Science, 13(3), 241-248. 
Russell, R. M. (2006). A review of the 2006 FIFA World Cup Germany. Insight: The FA Coaches Association Journal, Autumn/Winter, 24-26.

Scoulding, A., James, N., \& Taylor, J. (2004). Passing in the Soccer World Cup 2002. International Journal of Performance Analysis in Sport, 4(2), 36-41.

Stevens, J. P. (2009). Applied multivariate statistics for the social sciences (5th ed.). New York, NY: Routledge.

675 Tenga, A., Holme, I., Ronglan, L. T., \& Bahr, R. (2010a). Effect of playing tactics on achieving score-box possessions in a random series of team possessions from Norwegian professional soccer matches. Journal of Sports Sciences, 28(3), 245-255.

Tenga, A., Holme, I., Ronglan, L. T., \& Bahr, R. (2010b). Effect of playing tactics on goal scoring in Norwegian professional soccer. Journal of Sports Sciences, 28(3), 237-244.

Tenga, A., \& Larsen, O. (2003). Testing the validity of match analysis to describe playing styles in football. International Journal of Performance Analysis in Sport, 3(2), 90-102.

685 Tenga, A., Ronglan, L. T., \& Bahr, R. (2010). Measuring the effectiveness of offensive match-play in professional soccer. European Journal of Sport Science, 10(4), 269-277.
Tenga, A., \& Sigmundstad, E. (2011). Characteristics of goal-scoring possessions in open play: Comparing the top, in-between and bottom teams from professional soccer league. International Journal of Performance Analysis in Sport, 11(3), 545-552.

Travassos, B., Davids, K., Araujo, D., \& Esteves, P. T. (2013). Performance analysis in team sports: Advances from an ecological dynamics approach. International Journal of Performance Analysis in Sport, 13(1), 83-95.

Vogelbein, M., Nopp, S., \& Hökelmann, A. (2014). Defensive transition in soccer - are prompt possession regains a measure of success? A quantitative analysis of German Fussball-Bundesliga 2010/2011. Journal of Sports Sciences, 32(11), 1076-1083.

Wright, C., Atkins, S., Polman, R., Jones, B., \& Sargeson, L. (2011). Factors associated with goals and goal scoring opportunities in professional Soccer. International Journal of Performance Analysis in Sport, 11(3), 438-449.

Yiannakos, A., \& Armatas, V. (2006). Evaluation of the goal scoring patterns in European Championship in Portugal 2004. International Journal of Performance Analysis in Sport, 6(1), 178-188.

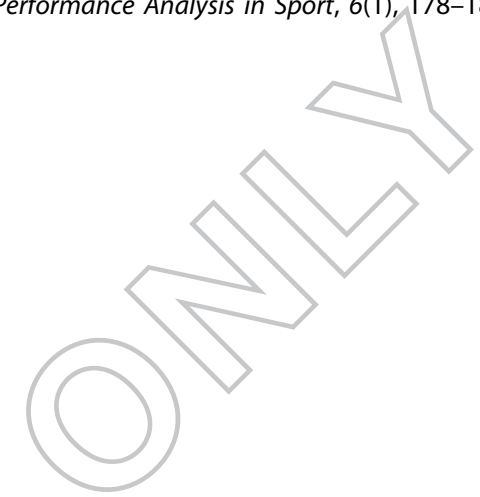

